\title{
Visualising urban energy use: the use of LiDAR and remote sensing data in urban energy planning
}

\author{
Nashwan Dawood*iD, Huda Dawood, Sergio Rodriguez-Trejo and Michael Crilly
}

\begin{abstract}
This paper explores the potential for using remotely sensed data from a combination of commercial and open-sources, to improve the functionality, accuracy of energy-use calculations and visualisation of carbon emissions. We present a study demonstrating the use of LiDAR (Light Detection And Ranging) data and aerial imagery for a mixed-use inner urban area within the North East of England and how this can improve the quality of input data for modelling standardised energy uses and carbon emissions. We explore the scope of possible input data for both (1) building geometry and (2) building physics models from these sources.

We explain the significance of improved data accuracy for the assessment of heat-loss parameters, orientation, and shading and renewable energy micro-generation. We also highlight the limitations around the sole use of remotely sensed data and how these concerns can be partially addressed through combinations with (1) open-source property data, such as age, occupancy, tenure and (2) existing stakeholder data sets, including building services and measured performance. We set out some of the technical challenges; addressed through data approximation (considering data quality and metadata protocols) and a combination of automated or manual processing; in the use, adaptation, and transferability of this data. We elucidate how the output can be visualised and be supported by many of industry-standard CAD, GIS, and BIM software applications hence, broadening the scope for realworld applications. We demonstrate the support of commercial interest and potential drawing evidence from primary market research regarding the principal applications, functionality, and output.

In summary, we conclude on the benefits in the use of remotely sensed data for improved accuracy in energy use and carbon emission calculations, the need for semantic integration of mixed data sources and the importance of output visualisation.
\end{abstract}

Keywords: Remote sensing, LiDAR, Energy modelling, Urban planning

\section{Background}

Accurate alternatives for collecting information that ease geometry models creation and calculation of energy performance at individual dwelling or at neighbourhood level are needed in order to improve quality of information at disposal for architects, urban planners and authorities. A number of building physics based models have been developed in the past and some of the notable include Building Research Establishment's Housing Model for Energy Studies (Shorrock and Dunster, 1997); UK Domestic Carbon Model (Boardman et al. 2005) and

\footnotetext{
* Correspondence: n.n.dawood@tees.c.uk

Center for Construction Innovation and Research, Teesside University, Middlesbrough TS1 3BA, UK
}

Community Domestic Energy Model (Firth et al. 2010). All these models have the same energy calculation engine which is BREDEM (Building Research Establishment Domestic Energy Model) and the Standard Assessment Procedure (SAP) which is recommended by the Department Of Business Energy And Industrial Strategy (BEIS) in the UK as the main tool to underpin BREDEM for assessing and comparing energy performance of dwellings. Accurate energy baselines for domestic buildings and neighbourhoods need that the models incorporate accurate raw data which collection can be expensive and time consuming. Generalised access to energy calculation models requires a skillset which most of the urban planners haven't yet acquired, and energy assessment usually 
relies on rough estimation of raw data making the energy calculation inaccurate. In this context, this paper addresses the issue of raw data availability and accuracy through the development of new processes and techniques for data collection and in particular the automated process of capturing dimensions and footprint of dwellings through the combination of OSL (Ordinance Survey and Landmap) data and deployment of LiDAR and remote sensing as means for aerial and terrestrial imagery. In addition, this captured geometrical data is further integrated with opensource and publically available data for a faster and more accurate energy calculations integrating data from available statistical sources, such as census data, deprivation and neighbourhood statistics data from ONS (Office of National Statistics), HEED (Homes Energy Efficiency Database) and EHS (English Housing Survey). This is a multi-source novel way of capturing and processing data for energy appraisal and visualisation. The remainder of this paper discuss the main technique used to capture data, dealing with errors and data cleaning, integration with other data bases and initial results from a case study.

The next section deals with remote sensing and LiDAR technology.

\section{Remote sensing \& Lidar technology Introduction to LiDAR}

LiDAR is an active remote sensing technology. It allows acquiring topographical information over surfaces at high Level of Detail (LoD), for large-scale urban areas. This data can be used for diverse aims, such as solar irradiance estimation for PV (photovoltaic) calculation (Robinson and Stone, 2004, Lukac et al., 2013), energy heating demand estimate (Tooke et al., 2014), and building type recognition and classification (Z. Lu et al., 2014) and this might represent an important input for the SAP tool calculation. The potential use of this technology is growing in line with the increased demand for accurate and updated data for energy calculation for dwellings and urban energy planners and decision makers, in a way that overcomes the limitations of plot cadastral and statistical information (Hermosilla et al., 2012).

This paper incorporates and extends on the methodology already established in Mhalas et al. (2014), where a framework that integrates visual systems, databases and a decision support system to rapidly evaluate energy performance of the dwellings is described. For this purpose, the Standard Assessment Procedure (SAP) was selected as a main element of the proof-of-concept. This paper focuses on the accuracy and availability of information that will be used for energy use using SAP as a methodology for energy calculation. Therefor the main thrust of this paper is on data gathering, cleaning, processing and use for accurate energy calculation.
The remainder of this section discusses the methods and techniques used in previous literature to pre-process, filter, noise reduction and conversion of the acquired LiDAR data and open source databases into usable object based formats in Geographical Information Systems (GIS) software tools ready to be used by energy calculation tools.

\section{Previous literature in LiDAR data processing}

Blaschke (2010) reviewed the state of the art of remote sensing technologies for Object Based Image Analysis (OBIA). The review highlighted the utilities, main limitations, as well as problems to be solved and where the main research has been focused, namely the high definition of images transformation through Fuzzy and Neural algorithm and other techniques. Tomljenovic et al. (2016) further develops the concept of use of LiDAR for 2D and 2,5D model extraction.

The use of LiDAR, within the urban built and energy related environment, has been mostly used to collect building physical features, assessment of the potential PV installation on rooftops and energy demand related studies (Lukac et al., 2013, Santos et al., 2014). Tooke et al. (2014) developed a methodology to utilise LiDAR data to aggregate a range of residential building energy and urban parameters and incorporate them with additional spatial data in order to calculate baseline estimates for energy demand for neighbouring regions within urban areas (see Fig. 1). The 3D shapes and the year of construction are incorporated within the statistically established energy performance data. Finally, both of the boundary conditions are considered, physical and environmental. The aim of the research is, based on this methodology, to systematically estimate the global energy demand for thermal uses in complete urban areas which is at the moment based on rough estimates.

Lukac et al. $(2013,2014)$ developed a methodology for determining a rating list of roofs' surfaces in relation to their solar potential and suitability for installing PV systems. LiDAR data from the urban environment has been used to obtain a 3D representation of the roofs. This data, along with irradiance historical files, have been used to estimate accurately the time dependent electricity generation from Photovoltaic Modules (PVMs) and the solar inverter, taking into consideration the non-linearity of the process and the accurate shadowing calculation inferred by the topological map created for the whole of urban area. These estimates are then compared with measurements obtained from a monitored PV plant. Jochem et al., 2009, Heinzel and Koch, 2011, Mongus and Zalik, 2012 presented methodology for the pre-processing of the LiDAR data using State of the Art classification methods. The obtained cloud points from LiDAR capture are converted into the urban elements and buildings' rooftops surfaces, with a twofold objective; firstly, to be able to accurately estimate the slopes and orientation of the PVM on the rooftops, and secondly, to calculate the 


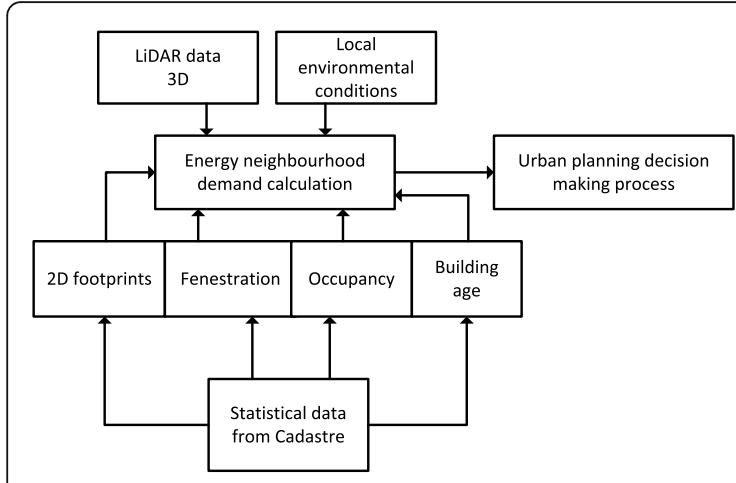

Fig. 1 Schema and workflow of Tooke et al. approach (2014)

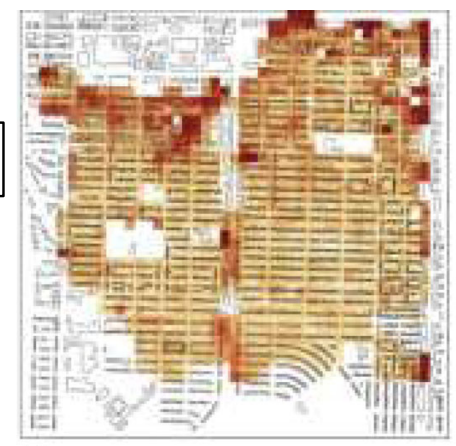

(a)

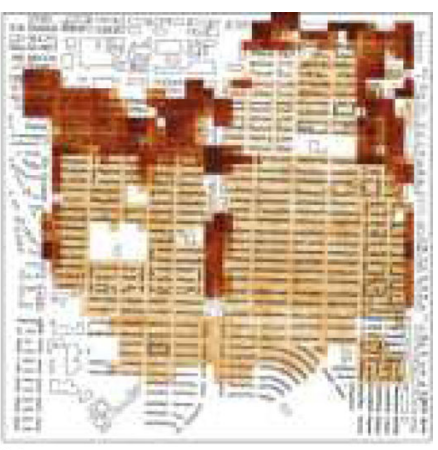

(b)

"Whet' instant shadowing during a whole year period (Lukac et al., 2013, Yuan et al., 2011). Lu et al. (2014) developed a methodology to generate a building information accurate geodatabase, which solves the limitations of obtaining data from parcel datasets that are often not reliable and up to date. Apart from the directly inferred geometrical data, the approach eases building and boundary area classification. The process includes three main tasks: (1) to delineate the boundaries of buildings and elements within the data, (2) to separate building data and (3) to classify the buildings into pre-established types.

It was concluded from previous efforts and approaches in building and neighbourhood energy modelling, that integration of information coming from various data sources is one of the greatest obstacles to tackle for application of LiDAR data in urban and city planning and operation. There is a challenge of managing urban change within the paradigm of the 'information city' (Kraemer \& King 1988). Municipalities and their partners require a supporting information infrastructure that supports a broad range of urban stakeholders to mutually understand and reinforce geophysical communities within urban neighbourhoods and localities (DohenyFarina 1996). The city map and urban model remain the most intuitive ways of structuring and accessing this urban information.

Appropriate and accurate data is crucial for understanding the viability of substantive urban energy systems and decision-making procedural systems that manage the urban system (Grossmann \& Watt 1992). In effect, there are complementary requirements from both technical and non-expert urban stakeholders in the use of urban energy information, its collection, analysis, sharing, and visualisation. Here, there is real potential for LiDAR data collected remotely at neighbourhood or city scale to simultaneously contribute to both, the technical and political decisionmaking requirements for better data. Initially it is ideal for information directly relating to building geometry. This geometry or 'property-based' data can be the basis for integration with wider and 'softer' aspects of urban planning and sustainability.

As summary from the previous literature review, it is possible to generate an estimation of an individual property energy use based on the attributes of the building supported, but not limited to cadastral plots (age / method of construction, geometry and services) and 'standardised' behaviour of the typical occupants. It is these property attributes that are well suited to the integration of LiDAR data on geometry with other open-source and publically available data sets that record the building performance characteristics. For example, the use of open-source database on the age of construction of the property, the use of stakeholders' own asset management database, systems upgrades to social housing as part of 'decent homes programme'.

This research presents a case study using a similar approach to the techniques demonstrated in Tooke et al. (2014). It presents the process to collect and pre-process data with the aim of estimating more accurately, the global energy demand for thermal uses in complete urban areas. Unlike in the Tooke's approach, the calculation for the baseline estimates of energy demand is based on SAP methodology shown in Mhalas et al. (2014). Database and assumptions are adapted to the case study. Visualisation and integration of the generated data offers a wider range of possibilities compared to the aforementioned approaches, combining and merging the results of the model with open source GoogleMaps and GoogleEarth. Figure 2 shows the workflow of the proposed approach for estimating Energy Demand, integrating different data sources.

The next section introduces the case study that was conducted in this research to demonstrate the techniques and methodologies used to process data for energy calculation.

\section{Methods}

\section{Capturing geometry data: a case study}

The objective of this section is to introduce a real life case study to demonstrate the procedure of capturing, 


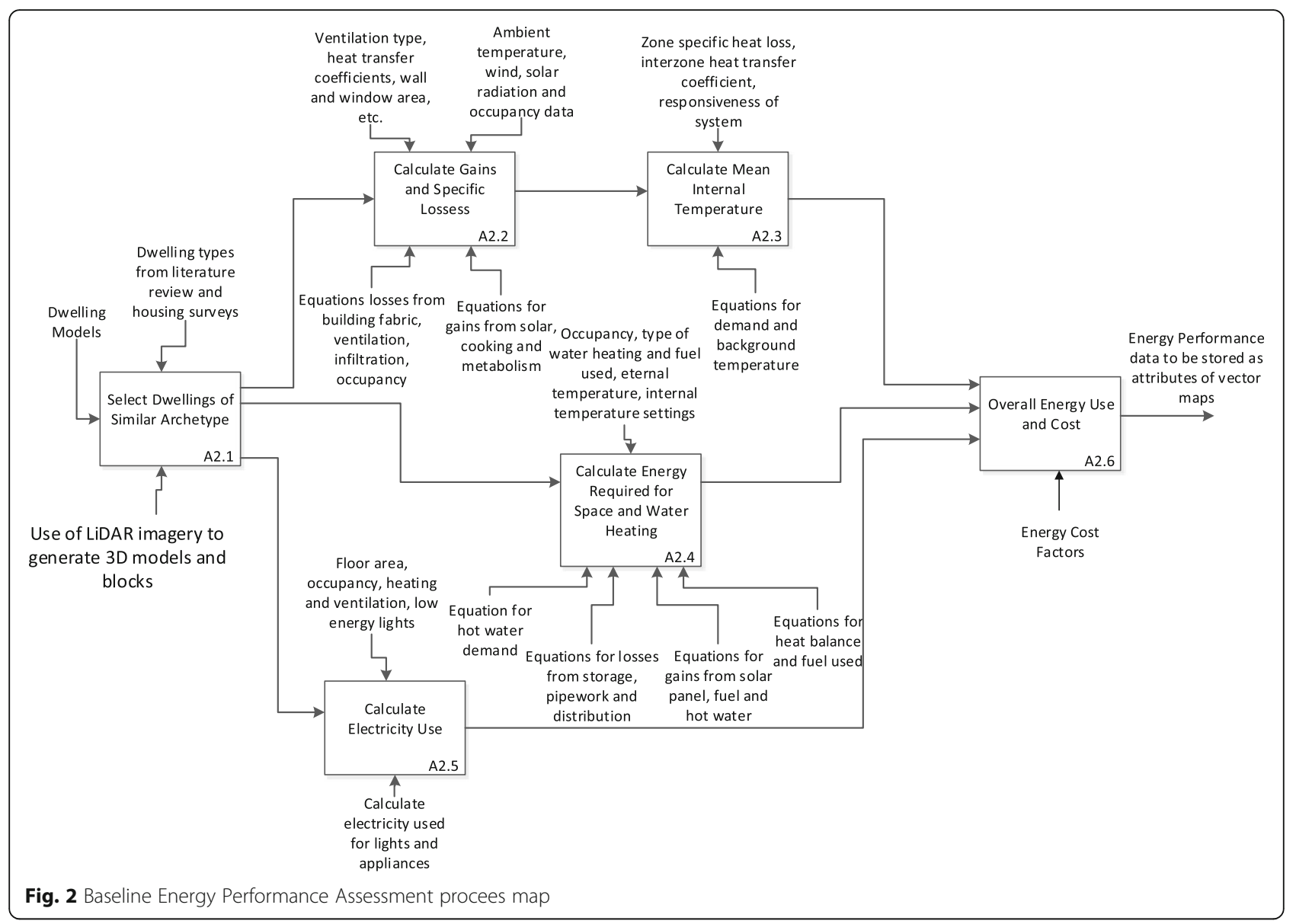

processing and using LiDAR information. A case study is selected in the inner area of west end of Newcastle upon-Tyne in the UK. This case study was part of SEMANCO (Semantic Tools for Carbon Reduction in Urban Planning), a European project co-funded by the European Commission within the 7th Framework Programme (http://semanco-project.eu/). The case study is based on an area which contains a variety of housing typologies, including significant multi-story and multioccupancy properties for a mix of different ownership patterns and tenures. The research project presented in this paper commissioned the LiDAR scanning of the project area for the purpose of calculating energy rating and ways in which these ratings can be improved through a more informed refurbishment programmes. The rationale was to overcome some of the costs and technical limitations of existing two-dimensional spatial data sets; for example, Ordnance Survey Landline / Master map that only held building ground floor footprints and no accurate building heights. Moreover, for the purpose of energy calculation and to augment the geometric information from LiDAR. This research has investigated the potential use of a variety of publically accessible and open-source data sets such as age of property, construction methods, type and age of boilers, etc.

The key intention for LiDAR data use was to support the estimation of urban energy use where there is a requirement for a high degree of accuracy in the building geometry. In addition, the commissioned LiDAR data included the necessary permission to integrate it with other data sets as part of an online energy modelling and decision-support tool. The rights to share this data and demonstrate the potential functionality when it linked to other data sets, is one of the initial outputs of this research work. Effectively, it allowed the research team to maintain an open-ended approach to the use and adaptation of the data set without being timelimited or legally restricted to the scope of use.

\section{Data specification and data collection}

The supply and collection of the LiDAR data was performed by a professional commercial provider (Blue Sky Company PLC). However, many factors and issues are realised regarding the specification of the data collection. Most significantly is the lack of any standard 
specification for the format, resolution and cleaning of the data, the following section discusses this.

\section{Data conversion and input}

The provided data used CityGML (City Geography Markup Language) and COLLADA (COLLAborative Design Activity) formats that are readable within many different standard software packages. Inner city is surveyed over a square kilometre using two separate scans that provided a terrain model and 'partially' auto-rectified structures. Typically, LiDAR data contained more than required details of specification in certain areas and significant gaps regarding surface materials and varied dimensions of these solid / opaque surfaces. There are some recent demonstrations of the application around the detail available and transferring or 'tracing' (Kimpton et al. 2010) CAD polylines over a polygon surface model / point cloud data. This is effectively a manual task to reduce the level of detail within the model. It turns a set of point cloud data into closed polygons - polygons with properties suitable for adding attributes and for visualisation. A similar approach is required for the neighbourhood scale to make the data usable for the purpose of estimating the energy use for individual properties.

The process of inferring 2D and 2,5D-classified information from the point cloud data through processing is time consuming and depends greatly on technical skills. However, the use of software such as ArcGIS (a complete, cloud based mapping platform) can automate these tasks easily through the implementation as modules, to obtain the features as the building footprint, height and shape. However, there is sparse development of this semiautomatic data processing, which depends a great deal on the density of points for the images at disposal. According to Henn et al. (2013) in the UK, the density is 0.5 points/ $\mathrm{m}^{2}, 1$ points $/ \mathrm{m}^{2}$ for Germany and 8 points $/ \mathrm{m}^{2}$ for the Netherlands. In the latest years, resolution available data has improved considerably, but at the time the survey was done, the density of data at disposal was at first instance not enough to conduct accurate identification. That can be the case in a majority of cases. Combination of usual $5 \times 5 \mathrm{~m}^{2}$ resolution files with LiDAR 4 points/ $\mathrm{m}^{2}$, as for the conducted survey in the case study, means a significant improvement in accuracy and data consistency. Ultimately, the data has two significant geometry values that need to be maintained as input measurements into a Reduced data Standard Assessment Procedure (RdSAP) or estimated SAP calculation process as the normal UK energy model. The input geometry is (a) the shape of the property; measured as the gross external footprint of the individual dwelling unit; and (b) the height of the property. Together, these input parameters allow an accurate calculation of heat-loss parameters around the extent of internal heated living space relative to the exposed surface areas as made up from the ground floor, external walls and roof. While there are limited opportunities for changing the shape (simplifying) and size (reducing) of homes to affect the heat loss parameters (Friedman 2005), building fabric interventions (typically internal or external insulation) can improve the thermal efficiency of specific building elements to reduce the heat loss. In most cases, improvement work to the building fabric will also be dependent upon the same geometry in terms of cost of treatment per square metre. Further interventions relate to possible upgrades to building services or the provision and connection to renewable and / or decentralized energy systems. These can likewise be attached as attributes to the property-based data that is consistent with similar scoping and qualitative assessments of stakeholder requirements (National Refurbishment Centre 2012) and those responsible for property management and maintenance, there is a practical focus on cost-effective and technically trusted approaches to refurbishment that requires good evidence base on accurate data.

In order to reach the point of using accurate building geometry data we need to identify any significant errors inherent within the original format of the commercially provided data and implement some data editing. Most of the errors reflect to inconsistencies of the polygons, differences to cadastral existing information, vegetation and unrecorded elements and structures. Figure 3 shows key steps in data handling processes.

\section{Errors within data collection}

To acquire useful data sets for energy monitoring, several types of initial data errors needed to be dealt with in advance. These errors relates to almost exclusively issues of 'bad geometry' arising from a combination of the angle of scanning of the terrain and properties together with the level of 'noise' within the LiDAR data. The 'noise' included errors from building overhangs, shadows, trees / vegetation and became more pronounced in areas where there were more complex geometries and structures. Figure 4 highlights some of LiDAR data issues and errors.

The best strategy in dealing with the various geometry errors is to create two separate data sets that hold discrete input data. The first deals with building footprints and the second with building heights. This strategy has proven most effective in a more complex process. Bremer et al. (2016) showed a process for which data is processed in three steps, from coarse Digital Surface Model (DSM) to fine DSM and making use of the close range domain given by the fine Digital Terrain Model (DTM) and the LiDAR points cloud. This information is checked against CityGML to obtain the final polygonal information in a $2.5 \mathrm{D}$ data file. The approach taken in this case study consists of checking the 


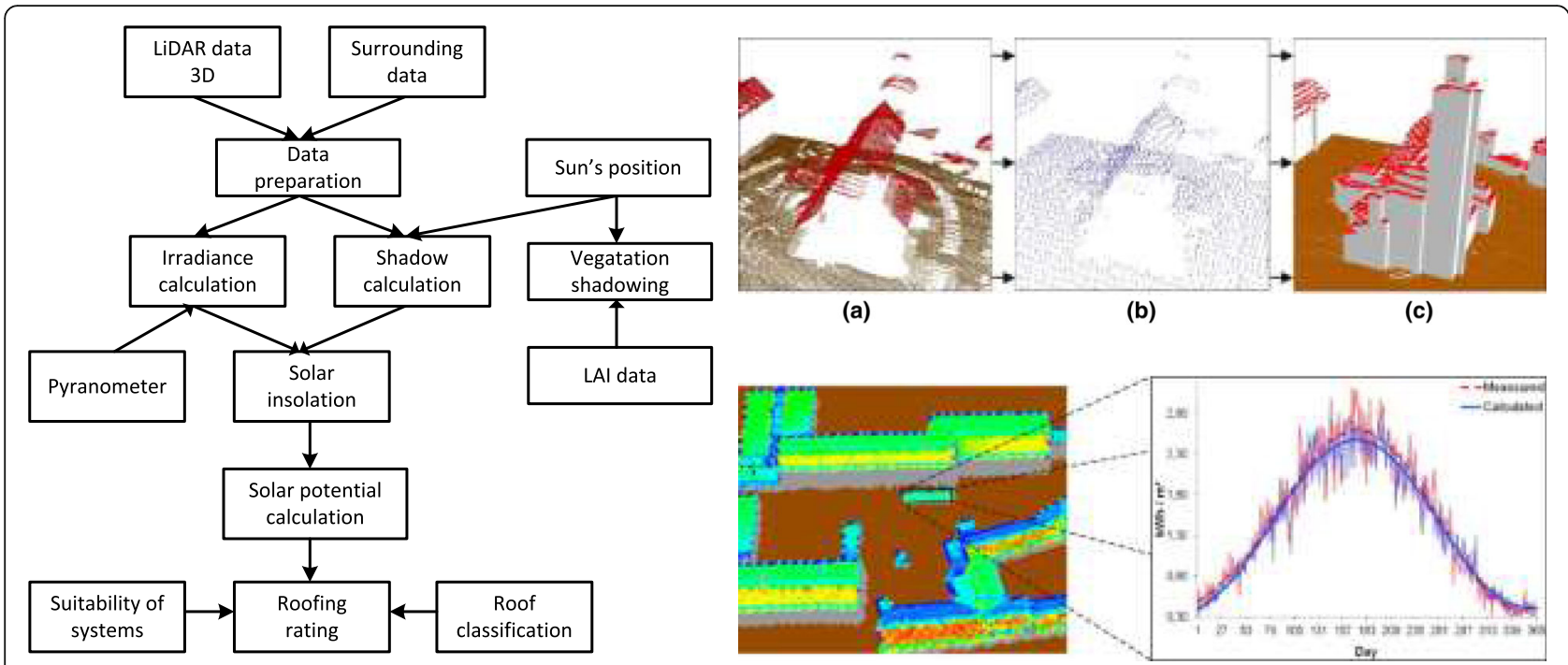

Fig. 3 Key steps in data handling processes in Lukač et al. approach (2013)

polygonal information from both 2D footprint and 3D height information, check for inconsistencies and solve clashes of information. Figure 5 depict a flow chart for cross data and inconstancies correcting and Fig. 6 shows an example of data error correction.

\section{Data cleaning and editing}

The first step in handling data is to pre-treat data by eliminating any basic errors/ outliers. Editing is carried out using the edit functions within ESRI's ArcGIS (see Fig. 6).

Overlapping polygons in the commercial data set are cleared of errors as they represent two properties occupying the same building footprint. These are merged and then split along an estimated property boundary. Furthermore, there were issues with sections such as disconnected polygons or 'gaps' in between terrace properties. These had their vertices snapped to match.

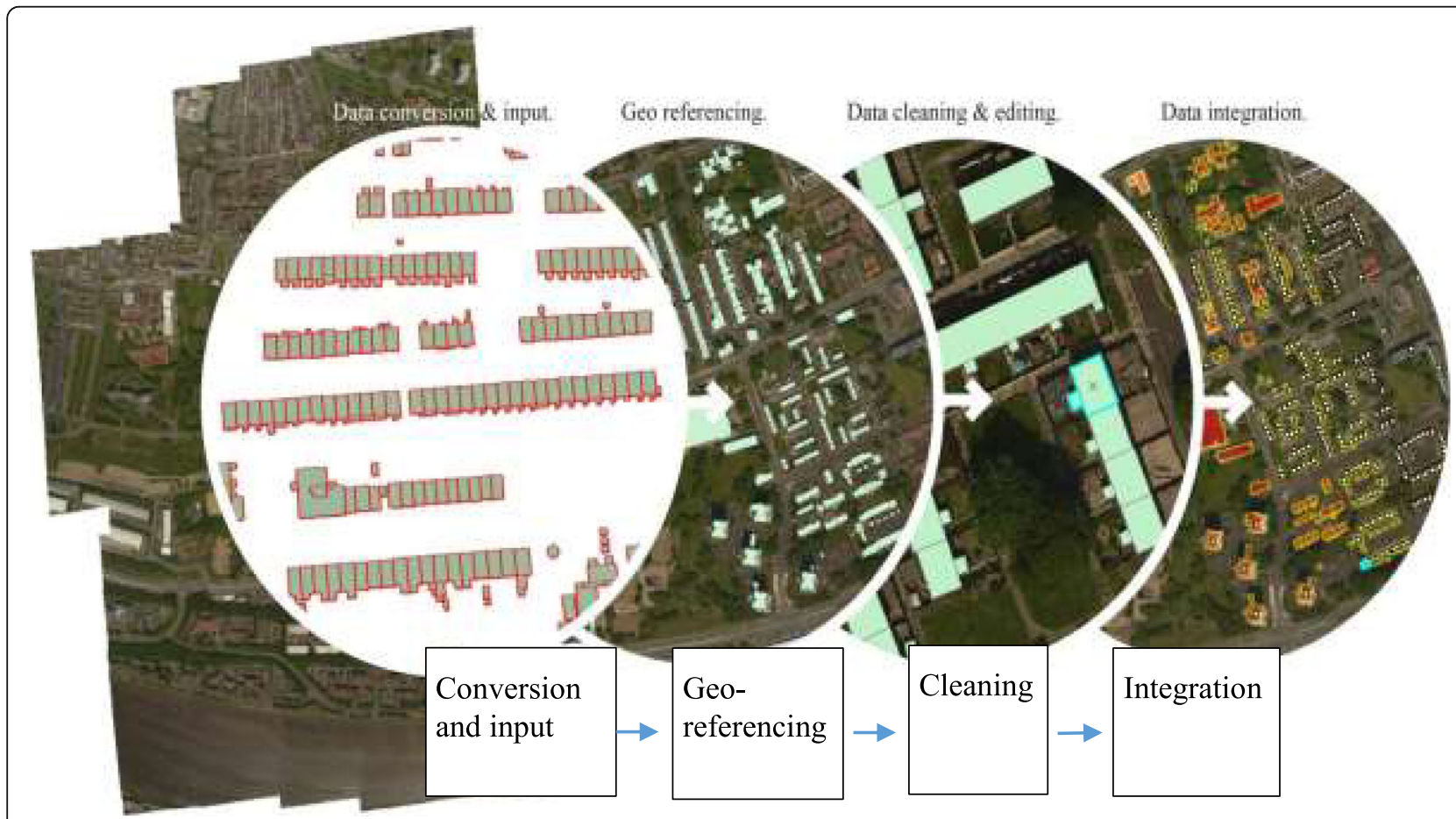

Fig. 4 Highlighting the initial LiDAR data errors 


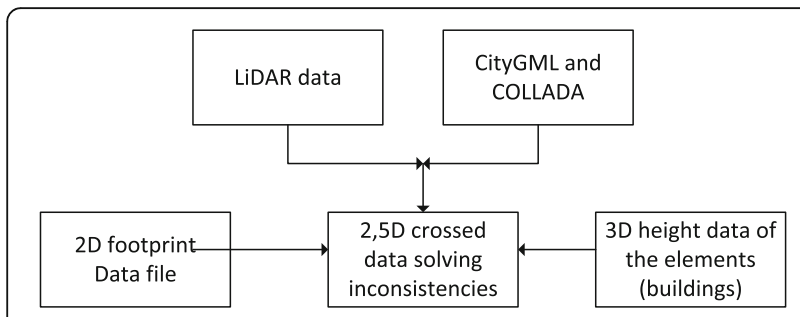

Fig. 5 Flowchart of the process for correcting polygonal inconsistencies

There are several instances of vertices existing within polygons that seemingly picked up variations in roof structures, chimneys / ventilation or in some instances in larger multi occupancy properties and non-residential units mechanical and engineering services plant on the roof. These are merged into single polygons with all extraneous vertices deleted. The result represents an accurate footprint data set.

\section{Identifying individual properties}

The next step was to separate the contiguous polygons / structures into individual properties. It is useful that the
LiDAR data is effective in picking up changes in external building heights. In an area of exaggerated topography in the west end of Newcastle where contiguous properties / terraced housing step up and down the slope, this suggests division between properties. However, in looking at the details, it failed to make a distinction between property boundaries because this boundary is in reality the thickness of a party wall between the individual properties. The change in roof heights coincided with the end (or in some instances the roof overlap) of the party wall and not the middle of the party wall. This becomes apparent when rear extensions have to be attributed to a particular property polygon. This could only be corrected manually using 'best-guess' information (Fig. 7) based on equidistant polygons to create properties of equal sizes as a typical property typology or using external information to property boundaries.

It is accepted that additional errors are re-introduced at each of these discrete stages within data cleaning and editing. Maintaining two separate data sets holding the footprint and height details separately is the best strategy to reduce the number of stages in data handling and thus reducing the potential of re-introducing any new errors when handling data.

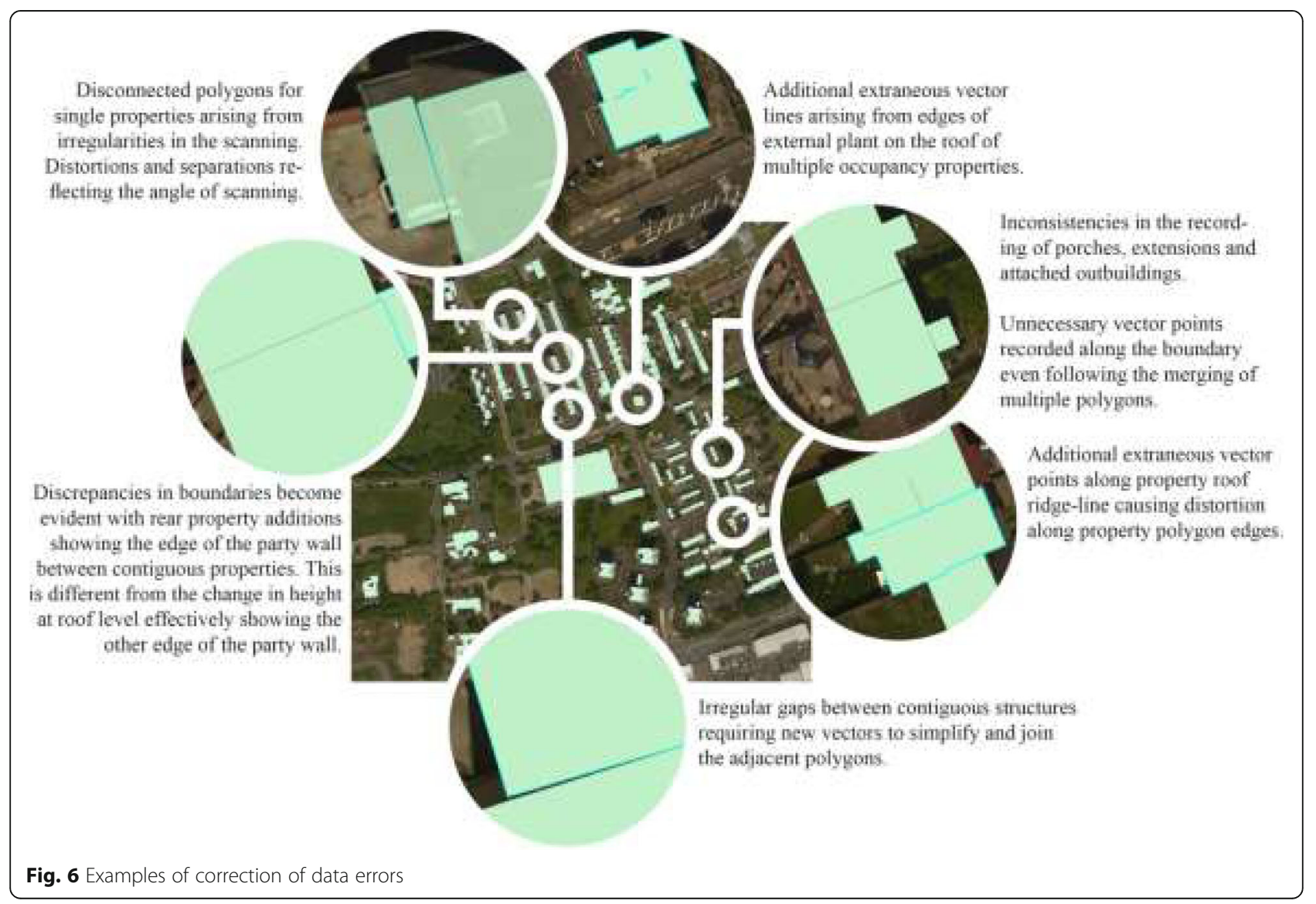




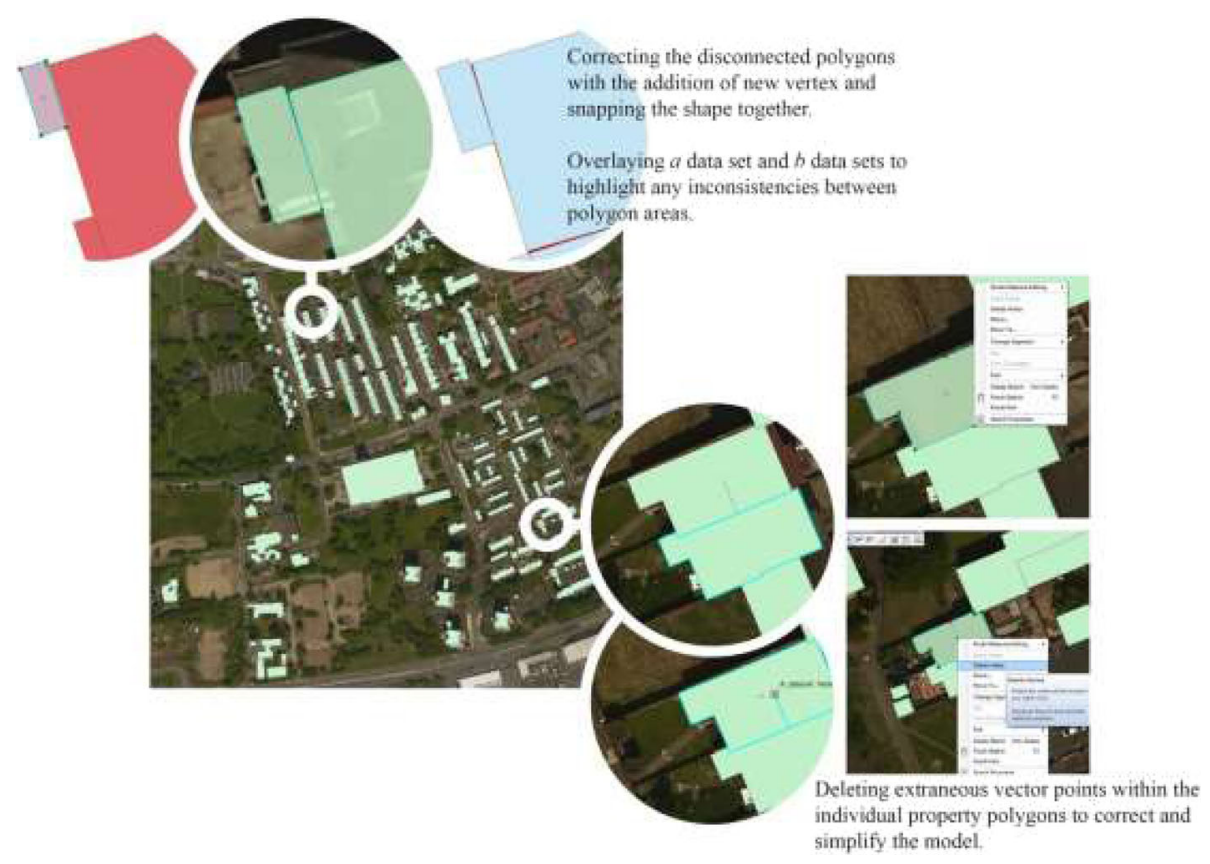

Fig. 7 Data editing to create individual property polygons

\section{Results and discussion}

\section{Integration with other data sets}

Thinking around the value of city models is rapidly changing in response to the power of computing but more significantly, the quantum of big data that now exists digitally.

We are entering into a world where everything is data. Planning has to deal with the scope of different sources of supporting evidence each using a variety of methodologies. There has to be an understanding of limits, unpredictability and allied to this are the procedural issues around irrationality, objectivity and political / cultural perceptions and definitions of qualitative aspects of behaviour, knowledge, attitudes and perceptions. Maps are clearly a useful way to explore data. Nonetheless, ultimately they are didactic tools. They are abstractions of reality and are designed primarily for exploration and understanding at strategic scales and early stages of decision-making. They will contain errors and have to be treated as tools for understanding rather than predicting energy usage.

Porter \& Neale (2000) acknowledged the development of the 'map' or 'model' from physical to digital, a paradigm shift in urban design and planning '... that hold(s) the potential for allowing the designer to move directly from concept to full scale construction'. In order to achieve this, the development of new methodologies to support the analysis and integration of large data sets has to be implemented (Aiden \& Michel 2013). Real 'big data' can be considered a replacement for intuition or guesswork where there are strategies in place for harvesting and mining every possible source (Baumgartner et al. 2012).

\section{LiDAR data use for energy performance evaluation with SAP engine}

Precise image data and aerial imagery is needed in order to conduct accurate neighbourhood energy performance evaluation. As well, use of published databases such as Homes Energy Efficiency Database (HEED), household surveys such as English House Condition Survey (EHCS), census and the Office of National Statistics (ONS) are used as data sources for input for the core SAP calculation engine as detailed in Mhalas et al. (2014).

Basing on this research, we realised that one major condition for the city model development, i.e. Newcastle Cruddas Park building areas (Fig. 10) included in the use case, was that it should support the demonstration of the baseline energy modelling SAP based software tool, with the variety of building and dwelling archetypes. To do that, accurate individual geometries of buildings needed to be put in place, in order to allow correct identification when geo-referencing and establishing links to the cadastral and other Database information sources. In the first instance, due to the resolution and also potentially the nature of the conveyed drive-by surveys, available data was not sufficiently consistent for these purposes, raising concerns related to the data processing regime and date of data capture, i.e. a number of buildings were missing from the map; the height of some buildings appeared to be updated in the MIMAS (2012); some of the extruded 3D blocks did not correspond to buildings at all. Additionally knowledge of the site, images and visual inspection analysis allowed the recognition of 


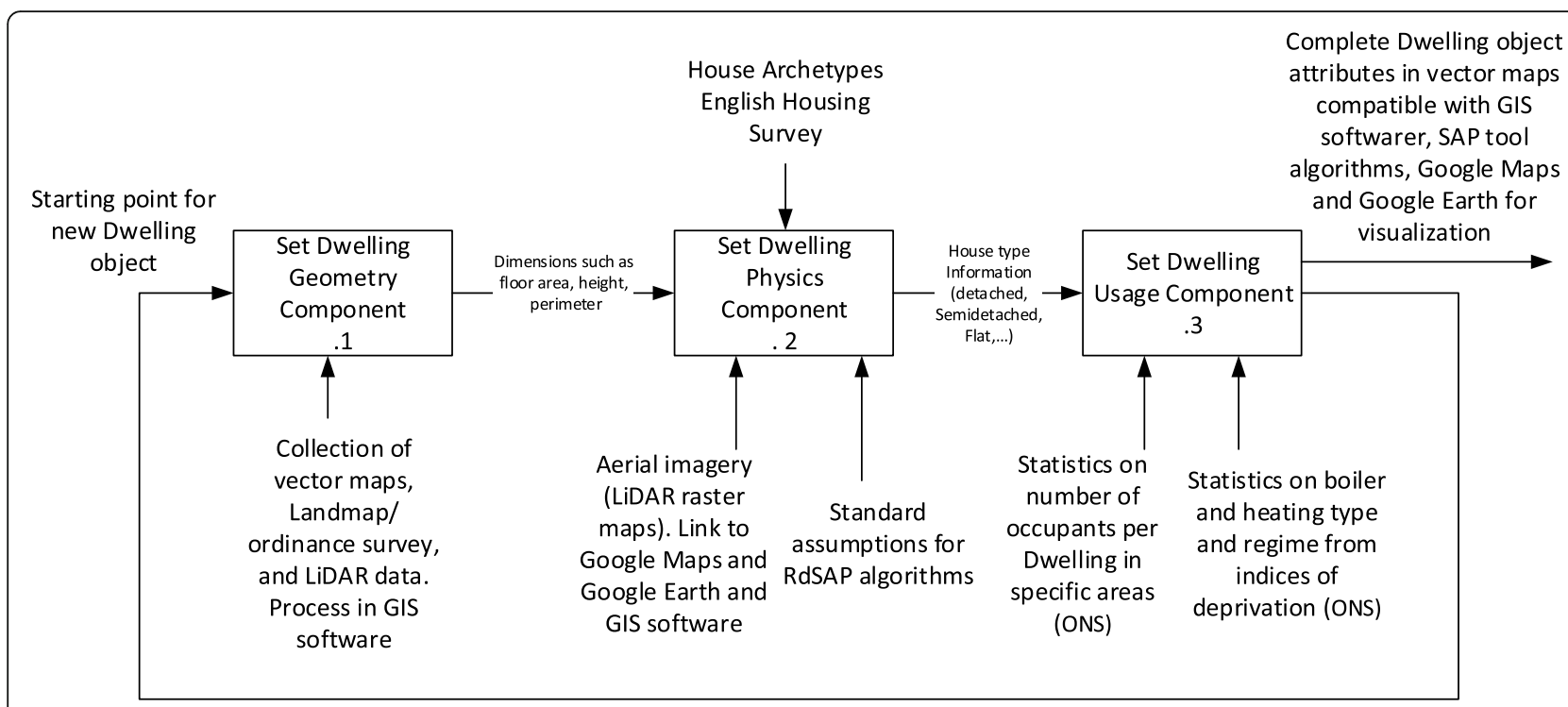

Fig. 8 Dwelling Objects Creation

other discrepancies, which meant a barrier for the definition of the energy performance map.

The selected process followed to generate and classify the individual building geometries according to the predefined archetypes is found in the IDEF0 map (Fig. 8), evolved from previous research found in Mhalas et al. (2014). The use of LiDAR was of help in resolving the aforementioned definition barriers in the Geometry and Physics components in Fig. 7. It allows the correct identification of individual buildings and a georeferenced location of them, granting integration of the COLLADA files with CityGML and open-source resources as Google Earth Pro. Both SHP vector files and CityGML files are superimposed on aerial map adding a layer to the open-sourced one.

This precise imagery serves as input for the SAP submodels for the specific building. This consists of extracting information for footprint, floor height, exposed perimeter wall area, and roof-area as well as opaque and window area and materials (U-values). Once the LiDAR file for a specific neighbourhood is in place, we use OS MasterMap layer and OS MasterMapTopography Layer to identify the buildings, and Visual Basic for Applications (VBA) to add information related to building physics and usage. ArcGIS features attribute replication for different buildings. Once the different buildings units and attributes have been defined ArcGIS developer allows SAP algorithms to be formulated into calculation tools, which will result in energy demand, heating and cooling demand, electricity demand, PV and Thermal solar generation. The process to obtain neighbourhood Baseline Energy Performance Assessment integrating the LiDAR data is shown in Fig. 2.
Visualisation of this data can be either be obtained with the aerial survey map, creating tailored layers to show the different output values, or integrate them into opensource platform layers as GoogleMaps or GoogleEarth. Both options need to create the layers using the KML layer creation. In that way visualisation of neighbourhood extended attributes becomes available for the platform users, and becomes a valuable source of information for urban planners, architects, and public services.

\section{Stakeholder data and user-defined mapping}

Big data tends to have veracity as well as volume, velocity, and variety. One of the key support tasks is to organise, structure and make sense of data. This is generally accomplished using one or more of the industry standard software packages, ArcGIS, AutoCAD, Sketchup and to a lesser degree, Google Earth. Additionally, there is an open-source mapping software and data, for example in the ESRI sponsored crowd-sourced mapping (Medeiros, 2013). Building energy data is just another element of this big data. Building energy use and carbon emissions have to be understood in the wider policy context and the complexity of the real world. There is a requirement to provide for users the ability to export, import, and connect with their own datasets to build on the functionality of the basic building geometry. Moreover, the significance of having remotely sensed data is that it provides accurate building geometry and other information. While initially, this geometry has value as input data for the calculation of the energy efficiency of buildings, this can be modified to incorporate a rage of additional functionalities when data is shared online and is linked to the individual property 
addresses for a more accurate measurement. For example, for the calculation of property refurbishment and renovation costs, building geometry is linked to a cost database or cost estimations.

Furthermore, the availability of an open-source threedimensional data is both limited and controlled and remarkably the same case study area of Newcastle in represented in Google Earth and effectively uses the same data from the same commercial supplier (see Figs. 9 and 10). Yet the functionality of this is limited to basic visualisation and the virtual exploration of the urban environment. The export functions, if any, are limited to two-dimensional aerial imagery, creating a level of frustration in achieving the level of accuracy, which is available through open-source data compared to the knowledge of the existence of accurate geometry. Yet this data is still currently just a collection of shapes without any property specific tagging. However, looking beyond the visualisation of the data are extractable geometry models that can be used for a variety of purposes, including acting as input data for more detailed urban design and architectural modelling.

\section{Discussion on the importance of visualising energy data and future work}

Urban planning and regeneration is complex as it brings together a broad range of stakeholders, as a mix of technical professionals and many different non-expert stakeholders that have their own personal and organizational experiences. Urban planning and management has become a two-way educational mutual learning process (Wals, 1996) that have connections between many consultation / participation exercises. These urban planning processes require the development of evidence base and information provision that is accessible and understandable to the broad scope of project stakeholders and in particular visual energy use. Indeed, Castells (2000) suggested that the appropriate sharing of urban data assists with the reform and legitimization of local democracy and governance. Data, including energy data, with all of its errors is best shared in a manner that is accessible to multiple stakeholders and is understandable to nontechnical users, extractable and editable for technical users.

The SEMANCO project reported in this paper has provided an online platform that provides access to widely dispersed energy related data about cities stored by many organisations. Thus, the platform supports improved energy analysis based on the assessment of existing data rather than estimates. This is performed using semantic data modelling that uses information stored in different places with different formats to create a multi-level energy model of an urban area. This can be further used to analyse the energy performance of individual buildings, neighbourhoods, districts and regions. Figure 11 shows a screen shot of the developed SEMANTIC tool for the Urban Energy Model.

The SEMANCO platform includes a set of tools to visualise and analyse a city's energy data. The visualisation combines interactive 3D models, tables and diagrams to display energy related data. Madrazo et al. (2013) stressed the importance of the visual threedimensional interface as a common language for a range of stakeholders becomes more apparent.

Although it is a significant way short of BIM standards, this is potentially the next step in the use of LiDAR information. Format and specifications in line with Construction Operations Building Information Exchange (COBie) and can be useful at the earliest stages of a design or construction plan of works. At present ISO 1006-2 sets the specification standards for ICT in construction projects and includes a detailed ontology for construction and building elements. This standard also sets out the design

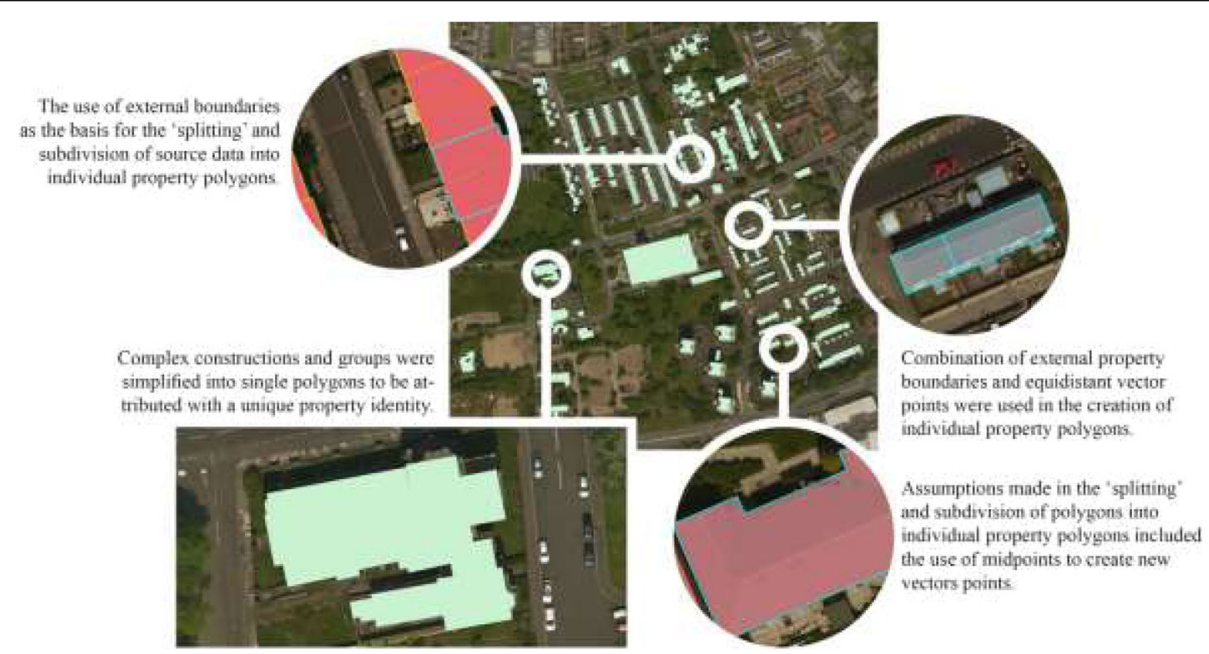

Fig. 9 Process for Data integration into GoogleEarth KML layer 


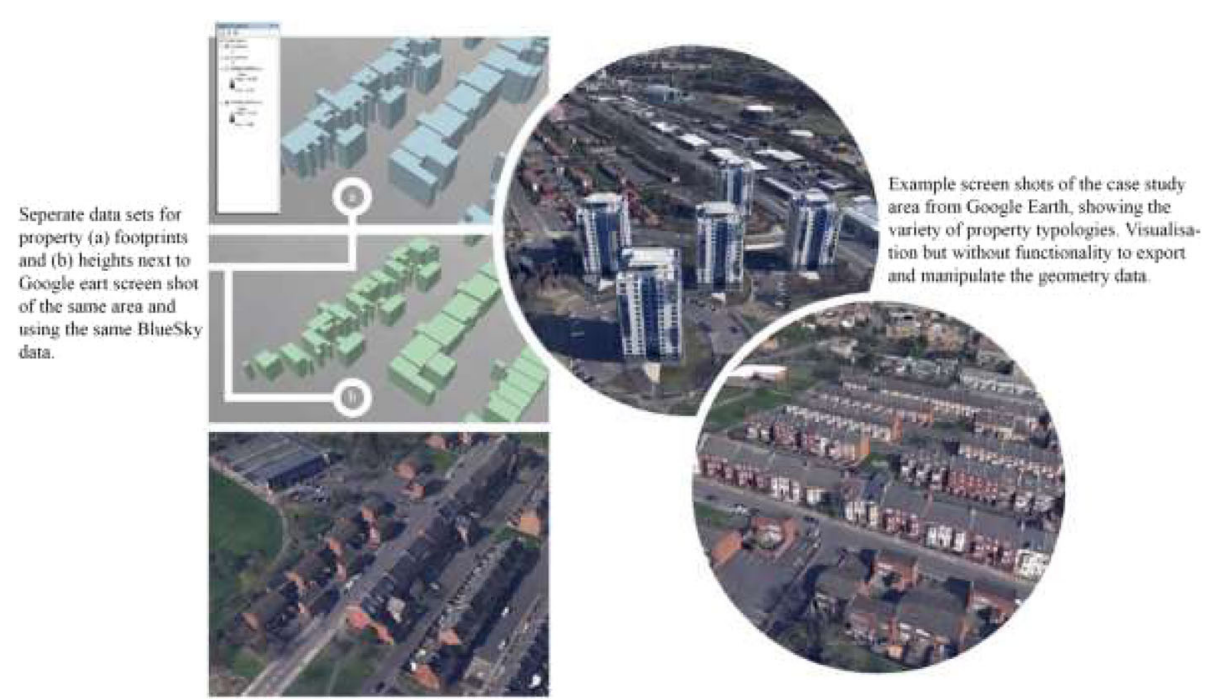

Fig. 10 Data visualization integration into GoogleEarth KML layer

\section{SEMANCO}

SEMANTIC TOOLS FOR CARBON REDUCTION WN UREAN FLANMTNG

\section{7}

Co-funded by the furoposn Oammiaion whin the oth fro

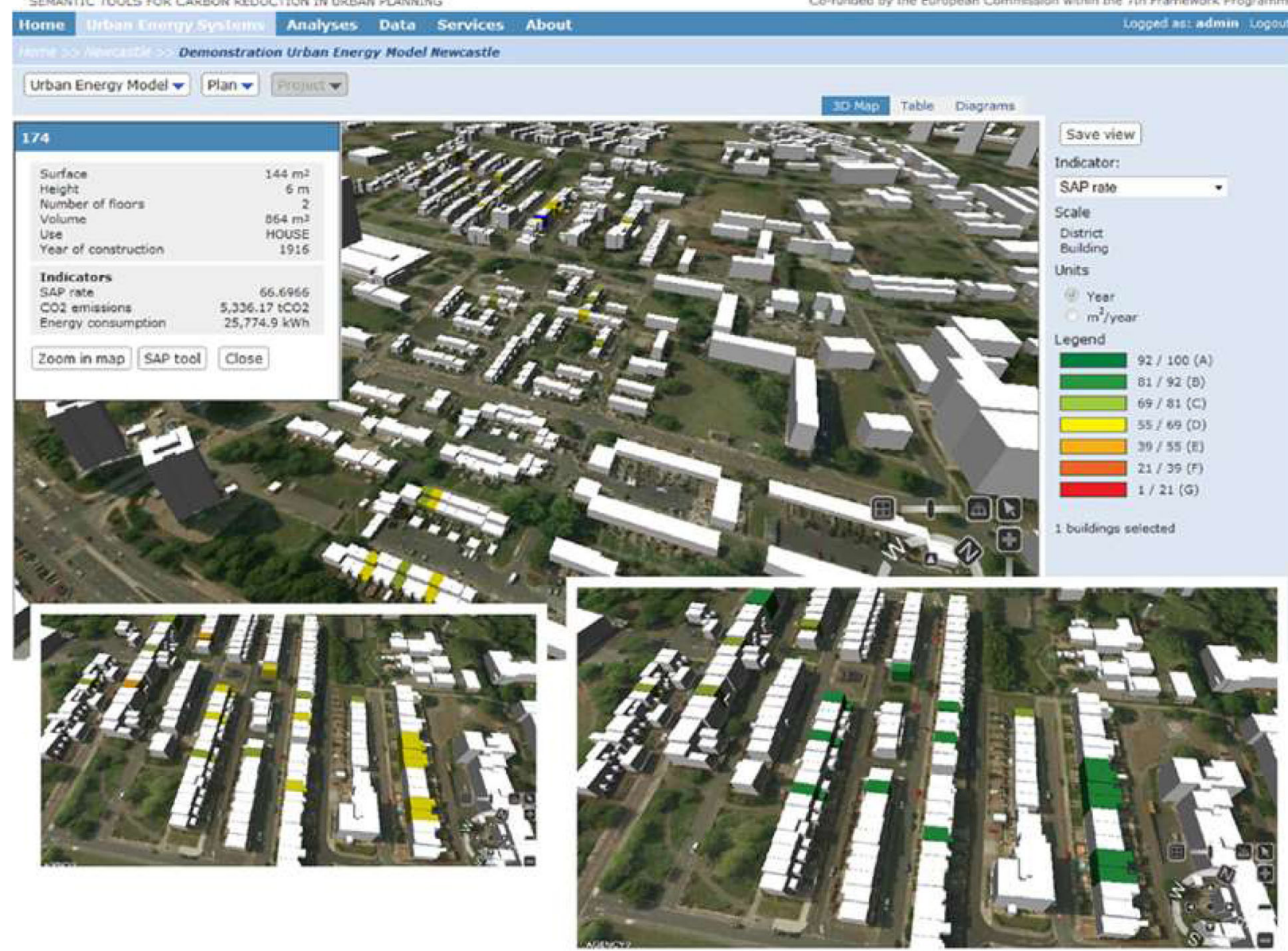

Fig. 11 Developed SEMANTIC tool for Urban Energy Model 
responsibilities between different professional stakeholders and the minimum requirements for technical / digital information change between the professionals. The standards overlap with COBie standards for data exchange, which sets out the specification of element properties in the form of an industry standard data language with specification properties. For the SEMANCO project, strategies are consigned to convert LiDAR datasets into accurate urban consistent information data to be used in COBie compliant BIM tools as well as specific energy related information fields have been merged to obtain an energy related ontology (Corrado et al., 2015). This is achieved by creating a formal vocabulary according to the Ontology Web Language specifications to assess the energy performance of an urban area.

As an increasing range of software packages use COBie standards for data input and integration, the challenge is to allow the use of remotely sensed LiDAR data on building geometry to be useful and timesaving as input data into these design software packages. Here the best versions are mostly automated from Revit or similar SOLIBRI compliance checking software. When remotely sensed data can be used with confidence at an early project stage and form part of the initial information exchange it will have significant new functionality. It has to be remembered that while most design packages and protocols are intended for new construction, around $80 \%$ of all construction projects still include existing structures for renovation, refurbishment, adaptation, or conversion (Itard \& Meijer 2009). An accurate representation of existing structures with a usable database containing the attributes and parameters of these structures will be hugely valuable addition to the initial business planning stages of many urban planning and regeneration projects.

It is also valuable to address compatibility of this methodology to parallel efforts in the direction of the W3C and Linked Building Data group to generate city models integrating data from disparate data sources such as LiDAR, photogrammetry and other survey methods considering OWL (Web Ontology Language). This points out the direction to follow, going beyond the building bound COBie and IFC models.

\section{Conclusion}

This paper presents a methodology to integrate remote sensing methodology and LiDAR techniques to visualise and calculate urban energy use in neighbourhoods, making use of proprietary and open source software tools. The paper emphasises the process to improve consistency of data for the assessment of energy use and calculation in urban settings and analyses the different barriers and problems raised in the undertaken research and solutions to them. The paper highlights the limitations around the current ways in which neighbourhood energy analysis and calculations are conducted and how these can be addressed through combinations with open-source property data and existing stakeholder data sets, including building services and measured performance. The paper shows how remote sensing data and LiDAR information can be captured, cleaned, processed and used.

This paper puts the thrust in ways to ease city models generation integrating LiDAR survey maps, especially considering neighbourhood energy analysis and benchmarking. In sum, the process improves the aspects of the model generation, process, analysis and visualisation, making use of widespread cloud based software tools. Unlike existing approaches, the possibilities open by the research shown in this paper enhances the use and handling of neighbourhood energy analysis and the integration with other visualisation tools enables not proficient users to access tailored and versatile information.

\section{Abbreviations}

BIM: Building information modelling; BREDEM: Building research establishment domestic energy model; CAD: Computer aided design; CityGML: City geography markup language; COBie: Construction operations building information exchange; COLLADA: COLLAborative design activity; DSM: Digital surface model; DTM: Digital terrain model; GIS: Geographical information system; LiDAR: Light detection and ranging; LoD: Level of detail; OBIA: Object based image analysis; PV: Photovoltaic, 4; PVMs: Photovoltaic modules, 5; RdSAP: Reduced data standard assessment procedure; SAP: Standard assessment procedure; SEMANCO: Semantic tools for carbon reduction in urban planning

\section{Acknowledgments}

This paper is based on applied semantic modelling research work undertaken as part of the SEMANCO project. SEMANCO is supported by the Seventh Framework Programme 'ICT for Energy Systems' 2011-2014, under the grant agreement Number 287534.

\section{Funding}

This paper is based on applied semantic modelling research work undertaken as part of the SEMANCO project. SEMANCO is supported by the Seventh Framework Programme 'ICT for Energy Systems' 2011-2014, under the grant agreement Number 287534

\section{Availability of data and materials}

The data can be shared and will be available on request.

\section{Authors' contributions}

Prof. Dawood: lead the research work into the visualisation and development of the research methodology. He has wrote the theoretical contents and research approaches. Dr. Huda Dawood, Dr. Sergio Rodriguez-Trejo and Dr. Michael Crilly contributed to the development and writing up of the visualisation model. Dr. Sergio Rodriguez-Trejo contributed to the theoretical framework and the energy engine part. All authors read and approved the final manuscript.

\section{Ethics approval and consent to participate}

The work did not involve any human subjects' participation or animal experiments and therefore this is 'Not Applicable'.

Consent for publication

Not Applicable.

Competing interests

There are no financial or non-financial interests by the authors to declare. 


\section{Publisher's Note}

Springer Nature remains neutral with regard to jurisdictional claims in published maps and institutional affiliations.

Received: 1 October 2016 Accepted: 12 November 2017

Published online: 29 December 2017

\section{References}

Aiden, E, \& Michel, J (2013). Uncharted: Big data as a lens on human culture. New York: Riverheadbooks pub. Penguin Group ISBN 978-1-59448-745-3.

Baumgartner, T, Hatami, H, Ark, V, Jon (2012). Find Big Growth in Big Data. In Sales growth: Five proven strategies from the World's sales leaders, (pp. 31-48). New Jersey: John Wiley \& Sons.

Blaschke T (2010). Object based image analysis for remote sensing, In ISPRS Journal of Photogrammetry and Remote Sensing, 65(1), 2-16 ISSN 0924-2716, http://www.sciencedirect.com/science/article/pii/S0924271609000884

Boardman, B, Darby, S, Killip, G, Hinnells, M, Jardine, C, Palmer, J, Sinden, G (2005). 40\% house. Oxford: Environmental Change Institute.

Bremer, M, Mayr, A, Wichmann, V, Schmidtner, K, Rutzinger, M. (2016). A new multi-scale 3D-GIS-approach for the assessment and dissemination of solar income of digital city models. Computers, Environment and Urban Systems, 57, 144-154.

Castells, M. (2000). Urban sustainability in the information age. City, 4(1), 118-122.

Corrado, V, Ballarini, I, Madrazo, L, Nemirovskij, G. (2015). Data structuring for the ontological modelling of urban energy systems: The experience of the SEMANCO project. Sustainable Cities and Society, 14, 223-235.

Doheny-Farina, S (1996). The wired neighbourhood. Newhaven: Yale University Press.

Firth, SK, Lomas, KJ \& Wright, AJ (2010). Targeting household energy-efficiency measures using sensitivity analysis. Building Research and Information, 38(1), 24-41.

Friedman, A (2005). Ideas for the home front. In Heintzman, Andrew, Solomon, Evan (Eds.), Fueling the future, (pp. 307-322). Toronto: Anansi Press.

Grossmann, WD, \& Watt, KEF. (1992). Viability and sustainability of civilisations, corporations, institutions and ecological systems. Systems Research, 9(1), 3-41.

Heinzel, J, \& Koch, B. (2011). Exploring full-waveform LiDAR parameters for tree species classification. International Journal of Applied Earth Observation and Geoinformation, 13(1). 152-160 ISSN 0303-2434, http://www.sciencedirect. com/science/article/pii/S0303243410001145.

Henn, A, Gröger, G, Stroh, V, Plümer, L. (2013). Model driven reconstruction of roofs from sparse LIDAR point clouds. ISPRS Journal of Photogrammetry and Remote Sensing, 76, 17-29 ISSN 0924-2716, https:// doi.org/10.1016/j.isprsjprs.2012.11.004.

Hermosilla, T, Ruiz, LA, Recio, JA, Cambra-López, M. (2012). Assessing contextual descriptive features for plot-based classification of urban areas. Landscape and Urban Planning, 106(1), 124-137 ISSN 0169-2046.

Itard, L, \& Meijer (2009). Towards a Sustainable Northern European Housing Stock: Figures, Facts and Future (sustainable urban areas). Amsterdam: IOS Press.

Jochem, A, Höfle, B, Rutzinger, M, Pfeifer, N. (2009, 2009). Automatic roof plane detection and analysis in airborne Lidar Point Clouds for Solar Potential Assessment. Sensors, 9(7), 5241-5262.

Kimpton, G, Horne, M, Heslop, D (2010). Terrestrial laser scanning and 3D imaging: Heritage case study - The black gate, Newcastle Upon Tyne. In ISPRS commission V technical symposium: Close range image measurement techniques, 22 June - 24 June 2010, Newcastle upon-Tyne.

Kraemer, KL, \& King, JL. (1988). The role of information technology in managing cities. Local Government Studies, 14(2), 23-47.

Lu, Z, Im, J, Rhee, J, Hodgson, M. (2014). Building type classification using spatia and landscape attributes derived from LiDAR remote sensing data. Landscape and Urban Planning, 130, 134-148 ISSN 0169-2046.

Lukac, N, Seme, S, Zlaus, D, Seme, S, Zalik, D, Stumberger, G, Zalik, B. (2014). Buildings roofs photovoltaic potential assessment based on LiDAR data. Energy, 66, 598-609.

Lukac, N, Zlaus, D, Seme, S, Zalik, B, Stumberger, G. (2013). Rating of roofs' surfaces regarding their solar potential and suitability for PV systems, based on LiDAR data. Applied Energy, 102, 803-812.

Madrazo, L, Sicilia, A, Nemirovski, G (2013). Shared vocabularies to support the creation of energy Urban Systems models. In Paper from ICT for sustainable places international conference, nice 9th-11th September.

Medeiros, João (2013) 'Maps made by millions'.Wired August pp48-49.

MIMAS (2012) Building Blocks. [Online] Available at: http://landmap.ac.uk/index php/Datasets/Building-Blocks/Building-Blocks. Accessed 2 Jan 2013.
Mhalas, A, Crosbie, T., Dawood, N., Kassem, M. (2014). 'Assessing Energy Improvement Potential from Efficiency and Renewable Interventions at Neighbourhood Level'. American Society of Civil Engineers. http:/tees. openrepository.com/tees/handle/10149/596114

Mongus, D, \& Zalik, B. (2012). Parameter-free ground filtering of LiDAR data for automatic DTM generation. ISPRS Journal of Photogrammetry and Remote Sensing, 67, 1-12.

National Refurbishment Centre (2012). Refurbishing the nation: Gathering the evidence. Watford: National Refurbishment Centre.

Porter, J, \& Neale, J (2000). Architectural supermodels: Physical design simulation. Oxford: Architectural Press.

Robinson, D, Stone, A (2004). Solar radiation modelling in the urban context. In Solar Energy, 77(3), 295-309 ISSN 0038-092X, http://www.sciencedirect.com/ science/article/pii/S0038092X04001161.

Santos, T, Gomes, N, Freire, S, Brito, MC, Santos, L, Tendorio, JA. (2014). Application of solar mapping in the urban environment. Applied Geography Journal, 51, 48-57.

Shorrock, LD, \& Dunster, JE (1997). The physically-based model BREHOMES and its use in deriving scenarios for the energy use and carbon dioxide emissions of the UK housing stock. Energy Policy, 25(12), 1027-1037.

Tomljenovic, I, Tiede, D, Blaschke, T. (2016). A building extraction approach for airborne laser scanner data utilizing the object based image analysis paradigm. International Journal of Applied Earth Observation and Geoinformation, 52(2016), 137-148 ISSN 0303-2434.

Tooke, TR, van der Laan, M, Coops, NC. (2014). Mapping demand for residential building thermal energy services using airborne LiDAR. Applied Energy, 127, 125-134 ISSN 0306-2619, https://doi.org/10.1016/j.apenergy.2014.03.035.

Wals, AEJ. (1996). Back-alley sustainability and the role of environmental education. Local Environment, 1(3), 299-316.

Yuan, H, Dai, Y, Xiao, Z, Ji, D, Shangguan, W. (2011). Reprocessing the MODIS leaf area index products for land surface and climate modelling. Remote Sensing of Environment, 115(5).

\section{Submit your manuscript to a SpringerOpen ${ }^{\circ}$ journal and benefit from:}

- Convenient online submission

- Rigorous peer review

- Open access: articles freely available online

- High visibility within the field

- Retaining the copyright to your article

Submit your next manuscript at $\gg$ springeropen.com 